\title{
RESEARCH
}

Open Access

\section{Impact of preoperative SYNTAX Scores on short-term outcome following coronary artery bypass grafting surgery in the patients with multi-vessels coronary artery disease}

Bassem Adel Ramadan, Mohamed Ahmed Zaki (D), Wahid Gamal El Din Etman, Mohamed Mostafa Agha, Mohamed Ahmed Sobhy and Wael Mahmoud Hassanein

\begin{abstract}
Background: SYNTAX Scores I (SSI) assesses the complexity of CAD; SYNTAX Score II (SSII) uses both SSI and other clinical variables, in estimation of 4 years mortality following both coronary artery bypass grafting surgery (CABG) and percutaneous coronary intervention (PCI) and gives recommendations for the best revascularization strategy in a specific patient. Our aim is to investigate the impact of both SYNTAX Scores on short-term outcome following CABG.

Results: Prospectively, we studied 150 patients with multi-vessels coronary artery disease, referred to perform, elective primary isolated CABG. All cases performed on pump CABG with aortic cross clamping, then followed up for 90 days postoperatively, for onset of mortality from all causes, myocardial infarction (MI), stroke, mediastinitis, and need for renal replacement therapy (RRT).

SSI showed a statistically significant association with in-hospital and 90 days mortality, Ml, and mediastinitis $(P=<$ $0.001,0.015,0.045$ respectively); SSII showed a statistically significant association with in-hospital mortality and 90 days mortality and need for renal replacement therapy $(P=0.007,0.043,0.012$ respectively); SSI is independent risk factor for overall mortality (OR 1.192, 95\% Cl 1.018-1.396) ( $P=0.029)$ and MI (OR 1.182, 95\% Cl 1.016-1.375).

Conclusions: SYNTAX Scores are good predictors of short-term outcome after CABG; increased SSI was associated with increased mortalities (in-hospital and total 90 days), MI and mediastinitis, increased SSII associated with increased mortalities (in-hospital and total 90 days), and need for RRT; SSI is independent risk factor for mortality and $\mathrm{MI}$.
\end{abstract}

Keywords: CABG, In-hospital mortality, RRT, SYNTAX Score I, SYNATAX Score II, MI, MACCE, Short-term outcome

* Correspondence: mohamed.a.zaki84@gmail.com

Faculty of Medicine, Alexandria University, Sultan Hussein Street, Al Khartoum Square, Alexandria, Egypt

\section{Springer Open}

(0) The Author(s). 2020 Open Access This article is licensed under a Creative Commons Attribution 4.0 International License, which permits use, sharing, adaptation, distribution and reproduction in any medium or format, as long as you give appropriate credit to the original author(s) and the source, provide a link to the Creative Commons licence, and indicate if changes were made. The images or other third party material in this article are included in the article's Creative Commons licence, unless indicated otherwise in a credit line to the material. If material is not included in the article's Creative Commons licence and your intended use is not permitted by statutory regulation or exceeds the permitted use, you will need to obtain permission directly from the copyright holder. To view a copy of this licence, visit http://creativecommons.org/licenses/by/4.0/. 


\section{Background}

Coronary artery disease (CAD) is the most common cause of death in the developed countries and is representing the commonest pathological entity facing the adult cardiologists and cardiac surgeons, with treatment options including optimized medical treatment, percutaneous Coronary Intervention (PCI) and/or coronary artery bypass grafting surgery (CABG) $[1,2]$.

Choice of the best revascularization strategy should be carried out by a multidisciplinary heart team, to ensure choice of the most suitable and durable revascularization method with focusing on the concept of complete revascularization, which leads to marked improvement of symptoms and reduction of the procedure-associated mortality and morbidity [3].

Marked improvement of PCI technologies in the past years with continuous emergence of newer generations of drug eluting stents resulted in replacement of CABG by PCI in many situations especially in the settings of acute coronary syndromes. CABG is still the revascularization strategy of choice in the management of patients with left main (LM) disease, diabetic patients with multivessels disease (MVD), and patients with complex anatomy of coronary arteries. As in these patients, CABG is associated with better long-term outcome, in the form of lower incidence of mortality and major adverse cardiac events [4-6].

Preoperative risk assessment is an integral part of the management of patients prepared for CABG, as the estimated surgical risk may affect the choice of the revascularization strategy. There are many valid risk scores that used for this purpose; both EuroSCORE II and STS scores are effective and accurate in estimation of inhospital and 30 days mortality post cardiac surgery but sharing a common disadvantage of neglecting the anatomical complexity of the coronary arteries [7-9].

SYNTAX Score I (SSI) is an anatomical scoring system that was derived from the SYNTAX trial (Synergy between PCI with Taxus and Cardiac Surgery), used for assessment of the anatomical complexity of coronary arteries, on the basis of SSI the complexity classified into 3 categories: low SSI (0-22), intermediate (23-32), and high (more than 33). In the patients with low SSI, PCI is not inferior to CABG (better option) as an option for revascularization, while in the patients with high SSI, CABG is the better option, as PCI in these patients associated with higher incidence of long-term mortality and MACCE. Main disadvantage of SSI is its neglection to the clinical conditions and comorbidities of the patient that may affect the outcome of surgery $[4,10,11]$.

SYNTAX Score II (SSII) combines both SSI and 7 clinical variables (age, sex, ejection fraction (EF), chronic obstructive pulmonary disease (COPD), peripheral vascular disease (PVD), unprotected LM disease, and creatinine clearance), in estimation of 4 years mortality following both CABG and PCI in a specific patient and gives a recommendation for revascularization: CABG, PCI, or both $[6,9,12]$.

The relationship between SSI and SSII with the outcome of CABG and/or PCI was proved to be mainly on the long-term follow-up, but the effect of these scores on the short-term outcome is still not clear, especially following $C A B G$, which is our aim in this study.

\section{Methods}

The aim of our study was to assess the impact of preoperative SYNTAX Scores on short-term outcome following CABG in the patients with MVD. This research was approved by our institution Ethics Committee, and written informed consent was obtained from all the participants included in this study.

We conducted a prospective, observational study on 150 patients with MVD, referred to our institute to perform, elective isolated CABG, in the period extended from August 2018 to November 2019. Patients with previous cardiac surgery, on maintenance hemodialysis, and those were not compliant during the follow-up period were excluded from the study. Preoperative data reviewed and both SYNTAX Scores were calculated using on-line program.

SSI calculated as a sum of points assigned to each individual lesion identified in the coronary arteries, in the coronary angiography with $>50 \%$ diameter narrowing in the vessels more than $1.5 \mathrm{~mm}$ diameter. The specific weight for each lesion differs according to the affected vessel and the dominance of coronary circulation.

Additional points added to total occlusion more than 3 months, calcified vessels, severely tortious vessels, bifurcation and trifurcation lesions, bridging collaterals, intraluminal thrombus, long segment lesion, aorto-ostial lesions, and diffusely diseased vessels. After introduction of the data, the program gives the SSI value.

SSII calculated by the same program, by combining the SSI with other clinical variables (age, sex, COPD, PVD, creatinine clearance, LV ejection fraction, and LM disease).

SSII calculator gives SSII for both CABG and PCI, expected 4 years mortality following both CABG and PCI and gives a recommendation for the revascularization strategy, whether CABG, PCI, or both.

Our study population was subjected to on pump CABG, with aortic cross clamping and cold crystalloid cardioplegia; we used skeletonized left internal mammary artery (LIMA) to left anterior descending coronary (LAD) anastomosis in all cases, saphenous vein graft used for the other anastomotic sites, and skeletonized right internal mammary artery (RIMA) used as the second arterial graft, in some selected cases. 
Intraoperative transesophageal echocardiography (TEE) is used for assessment of myocardial function and detection of new regional wall motion abnormalities (RWMA); it was done after induction of anesthesia and following weaning from cardiopulmonary bypass.

We followed up our patients for 90 days postoperatively for onset of all causes mortality, myocardial infarction (MI), stroke, mediastinitis, and need for renal replacement therapy (RRT).

In diagnosis of perioperative $\mathrm{MI}$, we depended on a combination between elevated $\mathrm{CKMB} /$ total $\mathrm{CK}$ ratio more than $10 \%$, together with new ECG changes (ST segment elevation, new left bundle block, Q wave, ventricular arrhythmias), clinical situation of the patient (hemodynamic instability, increased need for inotropes, cardiac arrest), and/or new RWMA that detected either by TEE or TTE, either intraoperatively or in ICU.

In patients who experienced significant ECG changes and/or hemodynamic instability in the perioperative period, the ratio between CKMB and total CK investigated, and immediate echo was done (TTE or TEE) according to the situation to detect new RWMA. A combination between the previously mentioned findings was diagnostic for perioperative MI.

Coronary angiography done for the cases presented with late onset MI after hospital discharge. RRT was initiated early in anuric patients who did not respond to maximum diuresis, oliguric patients with doubling of their serum creatinine within $24 \mathrm{~h}$, and oliguric patients with hyperkalemia who did not respond to anti-hyperkalemic measures. Newly developed neurological deficit with positive findings on brain imaging were diagnostic for stroke.

The data collected during the follow-up period were tabulated and prepared for the statistical analysis; these data did not include any private or personal information of our patients.

\section{Statistical analysis of the data}

Data were fed to the computer and analyzed using the IBM SPSS software package version 20.0. (Armonk, NY: IBM Corp). Qualitative data were described using number and percent. The Kolmogorov-Smirnov test was used to verify the normality of distribution. Quantitative data were described using range (minimum and maximum), mean, standard deviation, median, and interquartile range (IQR). Significance of the obtained results was judged at the $5 \%$ level. The used tests were Chi-square test, Fisher's Exact, Student $t$ test, $F$ test (ANOVA) (analysis of variance), Pearson coefficient, and Mann Whitney test

\section{Results}

We studied a total number of 150 patients with MVCAD; the preoperative data of our population are summarized and distributed in Table 1.
SYNTAX Score II recommended both CABG and PCI to 90 patients of our cohort (60\%), CABG only for 46 (30.7\%), while PCI only recommended for 14 patients (9.3\%). By following up these PCI recommended patients, we found among them one case had in-hospital mortality from MI. All our patients performed CABG, with mean graft number $2.95 \pm 0.70$, and we found a statistically significant association between the increasing SSI and number of bypass grafts $(\mathrm{P}=0.005)$.

Table 2 summarizes the incidence of mortalities and the studied complication, in our study population. As regards $\mathrm{MI}, 7$ of them were in the perioperative period (4.6\% perioperative $\mathrm{MI}$ ), while the remaining 3 cases presented with late onset $\mathrm{MI}$, after hospital discharge, also, one case with stroke presented in day 50 postoperatively and the remaining 4 cases in the perioperative period.

The distribution of mortalities in our study was as follows: 5 cases died from perioperative MI, 2 cases from respiratory failure, and one case from stroke (hemorrhagic transformation with midline brain shift). The additional 2 cases died after hospital discharge during follow-up period; one case from late onset MI and the other one were with undetermined etiology.

Table 3 summarizes the relation between preoperative SSI with the incidence of mortalities and studied complications; from this table, we had a statistically significant association between increasing SSI and the incidence of in-hospital mortality, total 90 days mortality, MI, and Mediastinitis.

Table 1 Distribution of the studied cases according to the preoperative data $(n=150)$

\begin{tabular}{lll}
\hline \multicolumn{1}{l}{ Sex } & No. & $\%$ \\
$\quad$ Female & & 35.3 \\
Age (years) & & \\
$\quad$ Mean \pm SD & $60.10 \pm 9.21$ & 80.0 \\
DM & 120 & 32.0 \\
LM disease & 48 & 28.0 \\
PVD $\quad$ COPD & 42 & 38.7 \\
& 58 & \\
EuroSCORE II & & \\
$\quad$ Mean \pm SD & $1.49 \pm 0.88$ & \\
EF \%, mean \pm SD & $55.50 \pm 8.27$ & \\
Cr. clearance (mean \pm SD) & $93.22 \pm 20.88$ & \\
SSI (mean \pm SD) & $26.24 \pm 5.84$ & \\
SSII CABG (mean \pm SD) & $26.96 \pm 10.85$ & \\
\hline
\end{tabular}

SSI SYNTAX Score I, cr. clearance creatinine clearance, SSII SYNTAX Score II, LM left main, $C O P D$ chronic obstructive pulmonary disease, $M I$ myocardial infarction, $P V D$ peripheral vascular disease 
Table 2 Incidence of mortalities and complications in study population $(n=150)$

\begin{tabular}{lll}
\hline & No. & $\%$ \\
\hline Overall mortality & 10 & 6.7 \\
In-hospital mortality & 8 & 5.3 \\
MI & 10 & 6.7 \\
Stroke & 5 & 3.3 \\
Need for RRT & 3 & 2.0 \\
Mediastinitis & 5 & 3.3 \\
\hline
\end{tabular}

We also investigated such association, with the preoperative SSII, and found a statistically significant association of SSII with in-hospital mortality, overall 90 days mortality, and need for RRT, which summarized in Table 4.

We did univariable and multivariable analysis of the incidence of total morality and each of the studied complication, with the preoperative clinical data of our patients (age, sex, DM, LM disease, creatinine clearance, EF \%, EuroSCORE II, SSI, and SSII) to study the association between them.

As regards the mortality, we found a statistically significant association of the overall mortality with SSI and SSII ( $P=0.015,0.048$ respectively) in the univariable analysis; also, SSI appeared to be an independent risk factor for mortality (OR 1.192, 95\% CI 1.018-1.396) $(P=$ 0.029 ) in the results of multivariable analysis; these relations demonstrated in Table 5.

Table 6 shows that incidence of MI showed a significant associated with increased SSI $(P=0.020)$ in univariable analysis; also, SSI appeared to be an independent risk factor for $\mathrm{MI}$, in the results of the multivariable analysis (OR 1.182, 95\% CI 1.016-1.375).

Incidence of mediastinitis showed a significant association with increasing age and EuroSCORE II $(P=0.019$, 0.006 respectively), while need for RRT was significantly associated with EuroSCORE II, SSII, and preoperative creatinine clearance $(P=0.045,0.006,0.027$ respectively) in their univariable analysis. In the multivariable analysis, none of the clinical data appeared to be an independent risk factor for mediastinitis or RRT. Stroke incidence, in our study, had no significant association with any of the clinical factors included in the analysis.

\section{Discussion}

SYNTAX Score I is an anatomical scoring system that used for assessment of the complexity of coronary arteries and estimation of long-term mortality and MACCE post PCI; SSII combines both SSI and 8 clinical variables, for estimation of 4 years mortality following both CABG and PCI for individual patient and gives its recommendation about the best revascularization strategy for the patient (PCI, CABG, or both). The impact of these scores on the short-term results following $C A B G$ is still unclear.

We prospectively studied 150 patients with MVD, performed elective primary isolated CABG, to assess the impact of preoperative SYNTAX Scores on the shortterm outcome. We followed up our patients for 90 days postoperatively (in hospital, visits, and phone calls), for onset of mortality, MI, stroke, mediastinitis, and need for RRT, then correlated the results obtained with the preoperatively calculated SYNTAX Scores and the preoperative clinical data. Table 2 summarizes the incidence of mortality and each of the studied complications in our study in 90-day follow-up period.

Does SSI, which reflects the anatomical complexity of the coronary arteries, affect the short-term outcome of CABG? This was the first question to be answered in our study. By reviewing the published studies in this topic, we found a little available data on the effect of SSI on the short-term results. Birim [10] and his colleagues searched the outcome of CABG in relation to SSI in 148 patients with LM disease, within 30 days and 1-year follow-up durations and found that the higher SSI was associated with greater incidence of mortality and MACCE within 30 days. Also, Alcazar [13] and his colleagues, when studied 716 patients with 3-vessel and/or LM disease, performed primary off pump CABG to

Table 3 Relation between preoperative SSI with the mortalities and studied complications $(n=150)$

\begin{tabular}{|c|c|c|c|c|c|}
\hline & \multirow[t]{2}{*}{$N$} & \multirow[t]{2}{*}{$\%$} & \multicolumn{2}{|c|}{ SSI (mean \pm SD) } & \multirow[t]{2}{*}{$P$} \\
\hline & & & Complicated & Non complicated & \\
\hline In-hospital mortality & 8 & 5.3 & $31.63 \pm 1.87$ & $25.94 \pm 5.85$ & $<0.001^{*}$ \\
\hline 90 days mortality & 10 & 6.7 & $30.75 \pm 2.91$ & $25.92 \pm 5.87$ & $<0.001^{*}$ \\
\hline MI & 10 & 6.7 & $30.55 \pm 4.79$ & $25.93 \pm 5.80$ & $0.015^{*}$ \\
\hline Stroke & 5 & 3.3 & $31.0 \pm 4.18$ & $26.08 \pm 5.83$ & 0.064 \\
\hline Need for RRT & 3 & 2 & $29.0 \pm 10.04$ & $26.18 \pm 5.77$ & 0.410 \\
\hline Mediastinitis & 5 & 3.3 & $27.70 \pm 1.10$ & $26.19 \pm 5.93$ & $0.045^{*}$ \\
\hline
\end{tabular}

$P P$ value for association between different categories, $M I$ myocardial infarction, $R R T$ renal replacement therapy, SSI SYNTAX Score I * Statistically significant at $P \leq 0.05$ 
Table 4 Relation between preoperative SSII with the mortalities and studied complications $(n=150)$

\begin{tabular}{|c|c|c|c|c|c|}
\hline & \multirow[t]{2}{*}{$N$} & \multirow[t]{2}{*}{$\%$} & \multicolumn{2}{|c|}{ SSII CABG (mean \pm SD) } & \multirow[t]{2}{*}{$P$} \\
\hline & & & Complicated & Non complicated & \\
\hline In-hospital mortality & 8 & 5.3 & $36.92 \pm 6.63$ & $26.40 \pm 10.78$ & $0.007^{*}$ \\
\hline 90 days mortality & 10 & 6.7 & $33.64 \pm 9.07$ & $26.48 \pm 10.84$ & $0.043^{*}$ \\
\hline MI & 10 & 6.7 & $28.68 \pm 10.07$ & $26.84 \pm 10.93$ & 0.606 \\
\hline Stroke & 5 & 3.3 & $29.44 \pm 7.82$ & $26.87 \pm 10.95$ & 0.605 \\
\hline Need for RRT & 3 & 2 & $42.40 \pm 13.50$ & $26.64 \pm 10.61$ & $0.012^{*}$ \\
\hline Mediastinitis & 5 & 3.3 & $35.68 \pm 4.60$ & $26.66 \pm 10.89$ & 0.067 \\
\hline
\end{tabular}

$P P$ value for association between different categories, $M I$ myocardial infarction, $R R T$ renal replacement therapy, SSII SYNTAX Score II

* Statistically significant at $P \leq 0.05$

evaluate the influence of SSI on both short- and longterm outcomes concluded that higher SSI is associated with higher in-hospital and long-term onset of MACCE but not with mortality.

In our study, we found a significant impact of SSI on short-term outcome, by founding a significant association between increased preoperative SSI and total 90 days mortality (mean $\pm \mathrm{SD}=30.75 \pm 2.9)(P<0.001)$, in-hospital mortality (mean $\pm \mathrm{SD}=31.63 \pm 1.87)(P<$ 0.001), MI within 90-day follow-up (mean $\pm \mathrm{SD}=30.55$ $\pm 4.79)(P=0.015)$, and mediastinitis (mean $\pm \mathrm{SD}=$ $27.70 \pm 1.10)(P=0.045)$.

Melina [14] and associates had another opinion, when they studied 191 patients with left ventricular dysfunction undergoing CABG with mean SSI was $32 \pm 13$, to assess the relation between the complexity of coronary arteries with short- and long-term outcome. They did not find a significant impact of SSI on the outcome in first 12-month follow-up but found that the greater complexity was associated with increased incidence of mortality and MACCE in 6-year follow-up duration. Moher [14] and his colleagues also found no impact of SSI on the postoperative outcome, within 2-year followup of SYNTAX cohort, who performed CABG in the original SYNTAX trial, and the outcome was related mainly to the completeness of revascularization, that was also, the main factor affected post CABG outcome in the study performed by Kato [15] and his working group, for the same purpose. These differences with our work may be due to the differences in study design, number of enrolled patients, associated comorbidities in each cohort, mean SSI for the study cohort, duration of the follow-up, and differences in the graft material and revascularization techniques.

The importance of SSII arises from its ability to individualize the decision making, by respecting the special patient-related clinical parameters that affect the outcome of surgery; Esper [11] and his colleagues performed a subgroup analysis of the patients enrolled in FREEDOM trial who received CABG and correlated their incidence of MACCE with preoperative SSI. They found a great impact of other factors, rather than SSI on the outcome of CABG in diabetic patients with MVD, as age and associated comorbidities. Finally, they recommended that SSI should not be used as the sole guiding tool, in choosing the revascularization strategy in diabetic patients and MVD.

In a multicenter trial conducted on 2961 patient performed isolated primary CABG, Gonzales [9] and his colleagues tried to assess the performance of STS Score,

Table 5 Univariable and multivariable analysis for the parameters affecting overall mortality (for total sample)

\begin{tabular}{|c|c|c|c|c|}
\hline \multirow[t]{2}{*}{ Mortality } & \multicolumn{2}{|c|}{ Univariable } & \multicolumn{2}{|c|}{ "Multivariable } \\
\hline & $\bar{P}$ & OR $(95 \% \mathrm{Cl})$ & $\bar{P}$ & OR $(95 \% \mathrm{Cl})$ \\
\hline Age & 0.391 & $1.034(0.957-1.118)$ & & \\
\hline Sex (female ${ }^{(\mathrm{R})}$, male) & 0.716 & $1.29(0.32-5.23)$ & & \\
\hline DM & 0.426 & $2.35(0.286-19.31)$ & & \\
\hline LM & 0.217 & $2.25(0.62-8.19)$ & & \\
\hline EF \% & 0.691 & $1.016(0.939-1.10)$ & & \\
\hline Creatinine clearance & 0.223 & $0.980(0.950-1.012)$ & & \\
\hline EuroScore II & 0.546 & $0.738(0.274-1.982)$ & & \\
\hline SSI & $0.015^{*}$ & $1.209^{*}(1.038-1.409)$ & $0.029^{*}$ & $1.192^{*}(1.018-1.396)$ \\
\hline SSII & $0.048^{*}$ & $1.069^{*}(1.001-1.14)$ & 0.114 & $1.059(0.986-1.136)$ \\
\hline
\end{tabular}

OR Odd's ratio, Cl confidence interval, SSI SYNTAX Score I, SSII SYNTAX Score II

\#All variables with $P \leq 0.2$ was included in the multivariable

*Statistically significant at $P \leq 0.05$ 
Table 6 Univariable and multivariable analysis for the parameters affecting MI (for total sample)

\begin{tabular}{|c|c|c|c|c|}
\hline \multirow[t]{2}{*}{$\mathrm{Ml}$} & \multicolumn{2}{|c|}{ Univariable } & \multicolumn{2}{|c|}{ \#Multivariable } \\
\hline & $P$ & OR $(95 \% \mathrm{Cl})$ & $p$ & OR (95\% Cl) \\
\hline Age & 0.191 & $0.959(0.902-1.021)$ & 0.712 & $0.985(0.907-1.069)$ \\
\hline Sex (female ${ }^{(R)}$, male) & 0.716 & $1.29(0.32-5.23)$ & & \\
\hline DM & 0.998 & - & & \\
\hline LM & 0.888 & $0.905(0.224-3.66)$ & & \\
\hline EF & 0.158 & $0.945(0.875-1.022)$ & 0.514 & $0.972(0.891-1.059)$ \\
\hline Creatinine clearance & 0.127 & $1.026(0.993-1.060)$ & 0.244 & $1.025(0.983-1.069)$ \\
\hline EuroScore II & 0.955 & $1.021(0.501-2.079)$ & & \\
\hline SSI & $0.020^{*}$ & $1.195^{*}(1.029-1.387)$ & $0.030^{*}$ & $1.182^{*}(1.016-1.375)$ \\
\hline SSII & 0.603 & $1.016(0.957-1.079)$ & & \\
\hline
\end{tabular}

OR Odd's ratio, $\mathrm{Cl}$ confidence interval

\#All variables with $P<0.2$ was included in the multivariate

*Statistically significant at $P \leq 0.05$

EuroSCORE II, and SSII in the prediction of both 30 days and 4 years mortalities. They found a better performance of EuroSCORE II and STS Score in prediction of 30 days mortality, while SSII was the most powerful predictor of long-term mortality.

Misumida [16] and his associates tested the prognostic value of SSII, when they retrospectively reviewed the data of 286 American Veterans with 3-vessel and/or LM disease performed either CABG or PCI. They compared the predicted 4 years mortality from SSII calculations with the observed 4 years mortality for the study population and found a well performance of SSII in estimation of 4 years mortality following both CABG and PCI at low and intermediate scores and underestimation of mortality in PCI group only with high scores.

In our study, we also found a prognostic value of preoperative SSII in evaluating the post CABG short-term outcome, as we found a significant association between increased preoperative SSII and in-hospital mortality $($ mean $\pm \mathrm{SD}=36.92 \pm 6.63)(P=0.007)$, total 90 days mortality (mean $\pm \mathrm{SD}=33.64 \pm 9.07)(P=0.043)$, and need for RRT (mean $\pm \mathrm{SD}=42.40 \pm 13.50)(P=0.012)$.

Should we respect SSII recommendations? Modolo [17] and his colleagues answered this question, when they reviewed SSII recommendations for the patients involved in EXCEL trial, and compared it with the actual treatment received, expected, and observed all causes mortality within 4 years. They found a higher observed mortality in the patients randomly assigned to PCI with SSII CABG recommendation, in comparison with their expected post CABG mortality, and reach the conclusion that non respect SSII CABG treatment recommendation was associated with higher mortalities. In our study, all patients were assigned to CABG with 14 of them had SSII PCI recommendation; among these patients, we had one in-hospital mortality from perioperative MI (7.1\%).
Analysis of mortality in our study showed that we had $5.3 \%$ in-hospital mortality and $6.7 \%$ total 90 days mortality. Our incidence was near to the results of Alberto [18] and his colleges, when they investigated the risk factors of mortality in their series of 1628 CABG patients within 30-day follow-up. They had 30 days mortality rate $8.7 \%$, with dialysis and neurological dysfunction were the main associated risk factors, while in our study MI was the main associated complication.

Also, our total mortality showed a significant association with SSI and SSII ( $P$ values were 0.014 and 0.048 respectively) in the results of its univariable analysis with the preoperative clinical data, while SSI appeared to be independent risk factor for mortality in the multivariable analysis (OR 1.192, 95\% CI 1.018-1.396).

Diagnosis of MI in the perioperative period is challenging, with a wide range of incidence in the literatures, according to the methods and definitions used in its diagnosis. This point in particular, approved by BellyCote [19] and his colleges, when they used different biomarkers (CKMB, Troponins), to study the differences in both incidence and prognosis of post CABG MI, when different definitions based on different biomarkers used in its diagnosis; they found that not only the incidence was different, but also, the prognosis according to the biomarker that used for definition of MI.

Diagnosis of perioperative MI does not depend on a single parameter; a combination of ECG changes (ST elevation, new $\mathrm{Q}$ wave, new LBBB) with hemodynamic instability, ventricular arrhythmias, elevated biomarkers, and/or new RWMA in the echo, is diagnostic. In these cases, early coronary angiography is very important to confirm the diagnosis, detect the etiology (graft or nongraft related causes), and provide treatment (ad hoc PCI) [19-21].

In our study, we used $\mathrm{CKMB} /$ total $\mathrm{CK}$ ratio > 10\%, as the biomarker for diagnosis of perioperative $\mathrm{MI}$; this 
biomarker used also by Rupperchet [21] and his working group, when they retrospectively studied 108 patients, suffered from post CABG ischemia and performed early postoperative coronary angiography, to evaluate the impact of early coronary angiography in improving the outcome in the cases associated with post CABG ischemia.

We had a total incidence of MI in 90-day follow-up $6.7 \%$ and $4.6 \%$ in the perioperative period. In PREVENT IV study which included a total number of 3014 patients performed CABG, the investigators studied the incidence, mechanisms, and prognosis of $\mathrm{MI}$ in both perioperative period and 2-year follow-up; they found the incidence of perioperative MI in their series 9.8\% [22].

All the previously mentioned studies and the recent guidelines on myocardial revascularization emphasize on the importance of coronary angiography, in cases with post CABG ischemia to improve the outcome. In our study, we relied only on the clinical, biochemical, and echo changes in diagnosis of MI in the perioperative period (lacking the facility of intraoperative or early postoperative angiography in our institute) and coronary angiography done for the patients who presented with late onset MI after hospital discharge. This issue demonstrates high incidence of mortalities, among the patients with MI in our series [3, 19-22].

Univariable analysis of MI incidence in relation to the preoperative clinical data showed a significant association with SSI (mean $\pm \mathrm{SD}=30.55 \pm 4.79)(P=0.020)$ that also appeared to be an independent risk factor for MI in the results of multivariable analysis (OR 1.182, 95\% CI 1.016-1.375) $(P=0.030)$.

We did not find recent papers that discuss the association between SSI and perioperative MI as a separate entity, but many authors included MI as one of the components of MACCE in their studies of the relation between SSI and post CABG outcome as Birim [10], Alcazar [13], Melina [23], Mohr [14], and their colleagues. Their results already compared with our results in a previous part of discussion.

Lack of studies that investigate the relation between perioperative MI as a separate entity and SSI is considered as a point of strength in our study.

We had 3.3\% of our patients stroked in 90-day followup period and $2.6 \%$ in the perioperative period; these numbers are near to the incidence in the literatures. We did not find a significant association between stroke incidence in our study population and any of the preoperative clinical factors included in the analysis [24].

The need for RRT in our study occurred in $2 \%$ of cases (3 patients), with no mortality among them. Ivert [25] and colleagues, on their series of 28,220 patients with primary isolated CABG, $0.6 \%$ of their patients needed a postoperative dialysis with 30 days mortality rate, among them was 26\%. Ranucci [26] and his working group, during their analysis of 7675 adult patient undergoing on pump cardiac surgery, showed that $1.7 \%$ of their patients needed dialysis with mortality rate, among them was $46.9 \%$. Absence of RRT associated mortality among our patients may be explained by the low number of cases, with a little chance for mortality to appear and/or early initiation of RRT in these patients that proved to be a very important factor in the reduction of mortality and improving the outcome, which is approved by a recently published meta-analysis on this topic [27].

Preoperative creatinine clearance, EuroSCORE II, and SSII of our study population showed a significant association with need for RRT ( $P$ values $=0.045,0.006,0.027$ respectively) when the univariable analysis of RRT with the preoperative clinical data was done, but none of them appeared as independent risk factor for RRT in the result of multivariable analysis.

Incidence of mediastinitis among our patients was 3.3\%; this incidence coincides with the results of Oliviera group [28] when they studied 1322 cases undergoing CABG and found the incidence of mediastinitis among their patients was $4.2 \%$.

The results of univariable analysis of mediastinitis incidence with the preoperative clinical data showed a significant association between mediastinitis with age and EuroSCORE II ( $P=0.019,0.006$ respectively), but none of them could be considered as independent risk factor of mediastinitis.

The strong relation between SSI and short-term outcome especially mortality and MI in our study may be explained by increased anatomical complexity of CAD is associated with technical difficulties as increased procedure time, number of grafts, and need for endarterectomy with target vessel reconstruction; all these are associated with increased mortality and morbidity. Also, increased SSI is always associated with poor distal run off in the native coronaries that contributes to a subsequent graft occlusion. These factors explain the higher incidence of mortalities and MI associated with high SSI (short-term complications that related mainly to anatomical complexity and technical factors).

Despite increased SSII is associated with significant increase in the mortality, it is less powerful than SSI in prediction of short-term post CABG outcome. We explained it by the fact that SSII value is affected by both SSI and the clinical situation of the patient. For example, a patient with high SSI and few comorbidities will have low SSII, while those with low SSI and multiple comorbidities will have high SSII. On the other hand, increased SSI is associated with more technical difficulties and procedure time with their impact on short-term outcome and vice versa. 


\section{Conclusion}

Both SYNTAX Scores are good predictors of short-term outcome after CABG; increased preoperative SSI (anatomical complexity of coronary lesions) in the patients undergoing CABG, was associated with increased postoperative mortalities (in-hospital and total 90 days), MI, and mediastinitis, in our study population. SSI also appeared to be an independent risk factor for short-term mortality and MI following CABG.

Increased preoperative SSII was associated with increased postoperative mortalities (in-hospital and total 90 days) and need for RRT in the patients undergoing CABG. We should also respect and follow the recommendations of SSII calculator, in deciding the revascularization strategy.

\section{Abbreviations}

CABG: Coronary artery bypass grafting surgery; CAD: Coronary artery disease; CK: Creatinine kinase; CKMB: Creatinine kinase isoenzyme MB; COPD: Chronic obstructive pulmonary disease; ECG: Electrocardiogram; EF: Ejection fraction; EuroSCORE II: European System for Cardiac Operative Risk Evaluation II; LM: Left main; MACCE: Major adverse cardiac and cerebrovascular events; MI: Myocardial infarction; MVD: Multi-vessels disease; PCl: Percutaneous coronary intervention; PVD: Peripheral vascular disease; RRT: Renal replacement therapy; RWMA: Regional wall motion abnormalities; SSI: SYNT AX Score I; SSII: SYNTAX Score II; STS Score: Society of Thoracic Surgeons risk score; SYNTAX: Synergy between PCI with Taxus and Cardiac Surgery; ANOVA test: Analysis of variance test

\section{Acknowledgements}

None

\section{Authors' contributions}

BR operated the cases and reviewed the results and data analysis. MZ collected the data, followed up the patients, interpret the data, and wrote and submitted the manuscript. WE reviewed the all steps of data preparation and results. MA reviewed the data collection and analysis. MS formulated the study design and review the results. WH formulated the study design, operated the cases, and contributed in data analysis and in writing the manuscript. All authors read and approved the final manuscript.

\section{Funding}

No funding was received.

\section{Availability of data and materials}

The datasets used and/or analyzed during this study are available from the corresponding author on reasonable request.

\section{Ethics approval and consent to participate}

Ethics approval was granted from the ethics committee of Alexandria Faculty of Medicine (IRB number: 00007555 FWA number: 00018699). Written informed consent was obtained from all the participants included in this study.

\section{Consent for publication}

Not applicable

\section{Competing interests}

The authors declare that they have no competing interests.

Received: 23 April 2020 Accepted: 19 June 2020

Published online: 02 July 2020

\section{References}

1. Benjamin EJ, Muntner P, Alonso A, Bittencourt MS, Callaway CW, Carson AP et al (2019) Heart disease and stroke statistics-2019 update: a report from the American Heart Association. Circulation 139:e56-e528
2. Hochman JS. (2019). International Study of Comparative Health Effectiveness with Medical and Invasive Approaches (ISCHEMIA Trial): primary report of clinical outcomes. Presented at: AHA 2019. November 16, 2019. Philadelphia, PA.

3. Neumann FJ, Sousa-Uva M, Ahlsson A, Alfonso F, Banning AP, Benedetto U et al (2019) 2018 ESC/EACTS quidelines on myocardial revascularization. Eur Heart J 40:87-165

4. Mohr FW, Morice MC, Kappetein AP, Feldman TE, Stahle E, Colombo A et al (2013) Coronary artery-bypass graft surgery versus percutaneous coronary intervention in patients with three-vessel disease and left main coronary disease: 5- year follow-up of the randomised, clinical SYNTAX trial. Lancet 381:629-638

5. Park SJ, Ahn JM, Kim YH, Park DW, Yun SC, Lee JY et al (2015) Trial of everolimus-eluting stents or bypass surgery for coronary disease. N Engl J Med 372:1204-1212

6. Campos CM, van Klaveren D, Farooq V, Simonton CA, Kappetein AP, Sabik JF III et al (2015) Long-term forecasting and comparison of mortality in the Evaluation of the Xience Everolimus Eluting Stent vs. Coronary Artery Bypass Surgery for Effectiveness of Left Main Revascularization (EXCEL) trial: prospective validation of the SYNTAX Score II. Eur Heart J 36:1231-1241

7. Sullivan PG, Wallach JD, loannidis JP (2016) Meta-analysis comparing established risk prediction models (EuroSCORE II, STS Score, and ACEF Score) for perioperative mortality during cardiac surgery. Am J Cardiol 118 : 1574-1582

8. Velicki L, Cemerlic-Adjic N, Pavlovic K, Mihajlovic BB, Bankovic D, Mihajlovic B et al (2014) Clinical performance of the EuroSCORE II compared with the previous EuroSCORE iterations. Thorac Cardiovasc Surg 62:288-297

9. Gonzales-Tamayo L, Campos C, Oliveira M, Dallan L, Jatene F, Mejia O (2018) P6360 STS, EuroSCORE II or SYNTAX II: which is the best score to assess mortality risk for complex coronary artery disease after CABG? Eur Heart J 39:1334

10. Birim O, van Gameren M, Bogers AJ, Serruys PW, Mohr FW, Kappetein AP (2009) Complexity of coronary vasculature predicts outcome of surgery for left main disease. Ann Thorac Surg 87:1097-1104 discussion 1104-1095

11. Esper RB, Farkouh ME, Ribeiro EE, Hueb W, Domanski M, Hamza TH et al (2018) SYNTAX Score in patients with diabetes undergoing coronary revascularization in the FREEDOM trial. J Am Coll Cardiol 72:2826-2837

12. Cavalcante $R$, Sotomi $Y$, Mancone $M$, Whan Lee $C$, Ahn JM, Onuma $Y$ et al (2017) Impact of the SYNTAX scores I and II in patients with diabetes and multivessel coronary disease: a pooled analysis of patient level data from the SYNTAX, PRECOMBAT, and BEST trials. Eur Heart J 38:1969-1977

13. Carnero-Alcazar M, Maroto Castellanos LC, Silva Guisasola JA, Cobiella Carnicer J, Alswies A, Fuentes Ferrer ME et al (2011) SYNTAX Score is associated with worse outcomes after off-pump coronary artery bypass grafting surgery for three-vessel or left main complex coronary disease. J Thorac Cardiovasc Surg 142(3):e123-e132

14. Mohr FW, Rastan AJ, Serruys PW, Kappetein AP, Holmes DR, Pomar JL et al (2011) Complex coronary anatomy in coronary artery bypass graft surgery: impact of complex coronary anatomy in modern bypass surgery? Lessons learned from the SYNTAX trial after two years. J Thorac Cardiovasc Surg 141:130-140

15. Kato Y, Takanashi S, Fukui T, Naruko T, Shibata T, Shimizu Y (2015) Does the complexity of coronary artery disease affect outcomes after complete revascularization with long segmental reconstruction of the left anterior descending artery using the left internal thoracic artery? Interact Cardiovasc Thorac Surg 21:308-314

16. Misumida N, Ahmed AE, Barlow M, Goodwin R, Goodwin E, Musa A et al (2018) Prognostic value of anatomical SYNTAX score and SYNTAX score II in veterans with left main and/or three-vessel coronary artery disease. Am J Cardiol 122:213-219

17. Modolo R, Chichareon P, van Klaveren D, Dressler O, Zhang Y, Sabik JF et al (2020) Impact of non-respect of SYNTAX score II recommendation for surgery in patients with left main coronary artery disease treated by percutaneous coronary intervention: an EXCEL substudy. Eur J Cardiothorac Surg 57:676-683

18. Santos CA, Oliveira MA, Brandi AC, Botelho PH, Brandi Jde C, Santos MA et al (2014) Risk factors for mortality of patients undergoing coronary artery bypass graft surgery. Rev Bras Cir Cardiovasc 29:513-520

19. Belley-Cote EP, Lamy A, Devereaux PJ, Kavsak P, Lamontagne F, Cook DJ et al (2020) Definitions of post-coronary artery bypass grafting myocardial infarction: variations in incidence and prognostic significance. Eur J Cardiothorac Surg 57:168-175 
20. Thielmann M, Sharma V, Al-Attar N, Bulluck H, Bisleri G, Bunge J et al (2017) ESC Joint Working Groups on Cardiovascular Surgery and the Cellular Biology of the Heart Position Paper: peri-operative myocardial injury and infarction in patients undergoing coronary artery bypass graft surgery. Eur Heart J 38:2392-2411

21. Rupprecht L, Schmid C, Debl K, Lunz D, Florchinger B, Keyser A (2019) Impact of coronary angiography early after CABG for suspected postoperative myocardial ischemia. J Cardiothorac Surg 14(1):54. https://doi. org/10.1186/s13019-019-0876-0

22. Hess CN, Lopes RD, Gibson CM, Hager R, Wojdyla DM, Englum BR et al (2014) Saphenous vein graft failure after coronary artery bypass surgery: insights from PREVENT IV. Circulation 130:1445-1451

23. Melina G, Angeloni E, Benedetto U, Monti F, Roscitano A, Serdoz R et al (2013) Complexity of coronary artery disease affects outcome of patients undergoing coronary artery bypass grafting with impaired left ventricular function. J Thorac Cardiovasc Surg 146:656-661

24. Gaudino M, Rahouma M, Di Mauro M, Yanagawa B, Abouarab A, Demetres $M$ et al (2019) Early versus delayed stroke after cardiac surgery: a systematic review and meta-analysis. J Am Heart Assoc 8:e012447. https://doi.org/10. 1161/JAHA.119.012447

25. Ivert T, Holzmann MJ, Sartipy U (2014) Survival in patients with acute kidney injury requiring dialysis after coronary artery bypass grafting. Eur J Cardiothorac Surg 45:312-317

26. Ranucci M, Aloisio T, Cazzaniga A, Di Dedda U, Gallazzi C, Pistuddi V (2018) Validation of renal-risk models for the prediction of non-renal replacement therapy cardiac surgery-associated acute kidney injury. Int J Cardiol 272:4953

27. Zou H, Hong Q, Xu G (2017) Early versus late initiation of renal replacement therapy impacts mortality in patients with acute kidney injury post cardiac surgery: a meta-analysis. Crit Care 21(1):150. https://doi.org/10.1186/s13054017-1707-0

28. Oliveira FDS, Freitas LDO, Rabelo-Silva ER, Costa LMD, Kalil RAK, Moraes MAP (2017) Predictors of mediastinitis risk after coronary artery bypass surgery: applicability of score in 1.322 cases. Arq Bras Cardiol 109(3):207-212

\section{Publisher's Note}

Springer Nature remains neutral with regard to jurisdictional claims in published maps and institutional affiliations.

\section{Submit your manuscript to a SpringerOpen ${ }^{\circ}$ journal and benefit from:}

- Convenient online submission

- Rigorous peer review

- Open access: articles freely available online

- High visibility within the field

- Retaining the copyright to your article

Submit your next manuscript at $\boldsymbol{\nabla}$ springeropen.com 